\title{
La amistad como núcleo de la vida política: actualidad del pensamiento de Aristóteles
}

\author{
María Celina Lacunza \\ Universidad Nacional de La Plata- IDIHCS \\ mclacunza@gmail.com
}

Recibido 30/06/16

Aprobado 28/08/16

\section{Resumen}

A partir de las últimas décadas del siglo pasado, la filosofía práctica de Aristóteles volvió a ser objeto de renovado interés. El resurgimiento de los estudios sobre la ciudadanía (Kymlicka, 1994) ${ }^{1}$ y el interés específico por la ciudadanía republicana y sus virtudes (Ovejero, 2005) ${ }^{2}$ pusieron en valor la concepción de la política como escenario de autorrealización y de sentido (Arendt, 2005) ${ }^{3}$. Este trabajo pretende sumarse a esta vertiente enfocándose en el tema de la amistad. Aristóteles trató con profundidad este tópico señalando la íntima relación entre los aspectos psicológicos y políticos en la comprensión del ser humano como un ser social. Para iniciar y culminar el desarrollo, elegimos como interlocutor al filósofo italiano Giorgio Agamben en quien nos permitimos mostrar la actualidad del pensamiento de Aristóteles. Agamben ${ }^{4}$ llama la atención sobre el concepto aristotélico de amistad como el espacio donde la persona se siente y percibe descubriendo y constatando el valor de la propia vida. Algunos interrogantes interpelan este escrito sin agotar su urgencia: ¿Es posible plantear el cultivo

\footnotetext{
1 KYMLICKA, Will y Wayne NORMAN. "El retorno del ciudadano. Una revisión de la producción reciente en teoría de la ciudadanía." En Cuadernos del CLAEH, 75, Montevideo, 1996. Pp. 81-112 disponible en http://www.insumisos.com/lecturasinsumisas/kymlicka.pdf

${ }^{2}$ OVEJERO LUCAS, Felix. Proceso Abierto: el socialismo después del socialismo, Barcelona, Kriterios. Tusquets Editores, 2005.

${ }^{3}$ ARENDT, Hanna. Qué es la política, Barcelona, Paidós, 2005.

${ }^{4}$ AGAMBEN, Giorgio. Profanaciones, Buenos Aires, Adriana Hidalgo Editora, 2005. [25 de septiembre de 2005] http://www.lanacion.com.ar/741397-la-amistad - La paginación corresponde a este sitio).
} 
de la amistad como un proyecto político viable? ¿Podrá ser la amistad el conjuro contra la vida abandonada y deshumanizada?

Palabras clave: Aristóteles, Agamben, política, amistad, homonoia

\section{Abstract}

Since the last decades of the previous century Aristotle's practical philosophy became an object of renewed interest again. The revival of citizenship studies (Kymlicka, $1994)^{5}$ and the specific interest in republican citizenship and its virtues (Ovejero, 2005) ${ }^{6}$ emphasized an understanding of politics as a setting for self-realization and sense (Arendt, 2005) ${ }^{7}$. In the present work we intend to follow this perspective, focusing on the topic of friendship. Aristotle addressed this topic thoroughly, highlighting the intimate relationship between the psychological and political aspects in the understanding of the human being as a social being. To initiate and culminate the development of the present work, we have chosen the Italian philosopher Giorgio Agamben to act as an interlocutor, allowing us to display the Aristotelian thought on present day. Agamben ${ }^{8}$ draws attention on the Aristotelian concept of friendship as the space where the person senses and perceives himself, the place where he discovers and confirms the value of his own life. Some questions appeal the present work without exhausting its urgency. Is it possible to propose the nurture of friendship as a viable political project? Could friendship be the spell against an abandoned and dehumanized life?

Keywords: Aristotle, Agamben, politics, friendship, homonoia

\footnotetext{
${ }^{5}$ KYMLICKA, Will y Wayne NORMAN. "El retorno del ciudadano. Una revisión de la producción reciente en teoría de la ciudadanía." En Cuadernos del CLAEH, 75, Montevideo, 1996. Pp. 81-112 Retrieved from http://www.insumisos.com/lecturasinsumisas/kymlicka.pdf

${ }^{6}$ OVEJERO LUCAS, Felix. Proceso Abierto: el socialismo después del socialismo, Barcelona, Kriterios. Tusquets Editores, 2005.

${ }^{7}$ ARENDT, Hanna. Qué es la política, Barcelona, Paidós, 2005.

${ }^{8}$ AGAMBEN, Giorgio. Profanaciones, Buenos Aires, Adriana Hidalgo Editora, 2005. [September 25, 2005] http://www.lanacion.com.ar/741397-la-amistad -
} 


\section{La opaca proximidad de los amigos según Giorgio Agamben}

En un breve escrito de principios de este siglo, Giorgio Agamben acude a Aristóteles para reflexionar sobre la amistad ${ }^{9}$. La ocasión de su escrito es, en algún sentido, una anécdota sobre el pensamiento. Hace unos años, conversando con Jaques Derrida sobre un seminario en el que el filósofo francés estaba trabajando, Agamben se interesó por la frase "leivmotiv" del proyecto: ó philoi, oudeís philos. "iOh amigos!, no hay amigos." Tal máxima, atribuida durante muchos años a Aristóteles, aparecía en Vidas de Diógenes Laercio convocando la atención de Montaigne, Nietzsche y, posteriormente, de Derrida.

Agamben observó que en ediciones modernas de esta obra la frase había sido modificada por otra más cercana al pensamiento del Estagirita: "aquel que tiene (muchos) amigos, no tiene ningún amigo" ${ }^{10}$. Investigando, supo que en 1616 el filólogo Isaac Casaubón, al editar la obra de Diógenes Laercio, había advertido el error de transcripción y corregido la sentencia: “(...) la enigmática lección de los manuscritos, se volvió así perfectamente inteligible, y, por eso, fue acogida por los filósofos modernos." ${ }^{11}$ Agamben se apuró entonces -según él mismo relata- a informar a Derrida del hallazgo. Cuando se publicó Politiques de l'amitié ${ }^{12}$ observó que su amigo no había modificado el lema apócrifo. Sobre el hecho, Agamben escribió “(...) no era ciertamente por un olvido (descuido): era esencial, en la estrategia del libro, que la amistad fuera, al mismo tiempo, afirmada y puesta en duda." En su opúsculo, el filósofo italiano se distancia de la posición de Derrida. Desde el comienzo, aprecia esta relación como ineludible aún en el acto y origen mismo del filosofar: “(...) en el mundo clásico esta promiscuidad y consustancialidad con el amigo se daba por descontada."13

\footnotetext{
${ }^{9}$ Op. Cit. AGAMBEN, Giorgio. Profanaciones.

${ }^{10}$ ARISTÓTELES. Ética a Nicómaco, [Traducción de Maria Araujo y Julián Marías], Madrid: Centro de Estudios Constitucionales, 1994 [EN] En esta obra encontramos el siguiente comentario a propósito de amistad entre los hombres buenos e iguales en virtud: "tales amistades son raras porque los hombres así son pocos." EN 1156b 23-24.

${ }^{11}$ Op. Cit. AGAMBEN, Giorgio. Profanaciones, p.2.

12 DERRIDA, Jaques. Políticas de la amistad seguido del oído de Heidegger, Barcelona. Ed. Trotta, 1998.

${ }^{13}$ Op. Cit. AGAMBEN, Giorgio. Profanaciones, p.2.
} 
Comentando el cuadro de Giovanni Serodini, Encuentro entre San Pedro y San Pablo en el camino al martirio, Agamben interpreta la escena como una "perfecta alegoría de la amistad". Los apóstoles se encuentran con sus rostros tan juntos que casi no pueden mirarse en el tumulto de soldados y gentío enardecido que los rodea. Una mirada atenta descubre que los santos estrechan sus manos por lo bajo en un gesto de hermandad íntima. Para Agamben el cuadro representa la "proximidad excesiva" que implica la amistad hasta el punto que los amigos no pueden reconocerse. Esta condición paradojal es lo que caracteriza para el filósofo esta relación: “¿Qué es, en efecto, la amistad sino una proximidad tal que no es posible hacer de ella ni una representación ni un concepto?”14

Para sostener su intuición, Agamben destaca un pasaje de la Ética a Nicómaco, ${ }^{15}$ en el que Aristóteles hace referencia al fenómeno en el que el sí mismo se descubre y percibe en el encuentro con un amigo quien -como un otro "yo"- permite no sólo percibirse "siendo" sino acceder al valor que entraña la existencia como algo "bueno" y "agradable". Para Agamben es precisamente esa "sin-estesia" (literalmente "percibir o sentir con otro") la que inaugura la dimensión ontológica y política de la amistad:

“(...) En términos modernos, se podría decir que "amigo" es un existencial y no un categorial. Pero este existencial -como tal, no conceptualizable-está atravesado sin embargo por una intensidad que lo carga de una potencia política. Esta intensidad es el syn, el "con" que reparte, disemina y vuelve compartible la misma sensación, la misma dulzura de existir." ${ }^{16}$

La presencia del amigo vuelve accesible la certeza interior de la propia existencia completando todo sentido en este acto trascendente en el que se verifica la identidad y la diferencia entre dos que son iguales. Jugando con el sentido de "sentir" y "consentir", Agamben aproxima dos dimensiones aparentemente excluyentes: lo necesario y lo elegido. En esta íntima filiación originaria hace fundar la praxis democrática y su legitimidad en el consenso: "El que esta sinestesia política originaria se haya convertido

\footnotetext{
${ }^{14}$ Op. Cit. AGAMBEN, Giorgio. Profanaciones, p. 4.

${ }^{15}$ Op.Cit, ARISTÓTELES, EN 1170 a 28- 1171 b 35

${ }^{16}$ Op. Cit. AGAMBEN, Giorgio. Profanaciones, p. 4.
} 
con el tiempo en el consenso al cual confían hoy sus suertes las democracias en la última, extrema y exhausta fase de su evolución es, como se suele decir, otra historia, sobre la cual los dejo reflexionar."17

El texto de Agamben, en su interesante complejidad, revitaliza reflexiones realizadas por Aristóteles hace más de dos milenios constituyendo una oportunidad para mostrar la actualidad y el valor de su concepción sobre la amistad.

\section{Opiniones cotidianas: las fronteras sociales de la verdad}

En el marco de las cuestiones sociales, Aristóteles parte de una endoxa ${ }^{18}$ cardinal: el ser humano es, fundamentalmente, un ser viviente que posee $\operatorname{logos}^{19}$. El logos es la posibilidad de nombrar, conversar, deliberar, elegir; habilidades decisivas para la constitución de una comunidad con un régimen soberano, la polis, que busque y sea a la vez parte del bien de sus miembros. Sobre este supuesto lo verdadero (aceptable, creíble) se descubre en el diá-logos:

La razón por la cual el hombre es, más que la abeja o cualquier animal gregario, un animal social es evidente (...) el hombre es el único animal que tiene palabra (logos) (...) la palabra es para manifestar lo conveniente y lo dañoso, lo justo y lo injusto, y es exclusivo del hombre, frente a los demás animales el tener él sólo el sentido del bien y del mal, de lo justo y de lo injusto y la comunidad de estas cosas es lo que constituye la casa y la ciudad. ${ }^{20}$

\footnotetext{
${ }^{17}$ Op. Cit. AGAMBEN, Giorgio. Profanaciones, p. 5.

${ }^{18}$ Ver nota 21.

${ }^{19}$ Logos designa razón, palabra o regla según el contexto. También refiere a otros significados derivados como argumento, justificación o bien discurso, relato, máxima. Logos es norma y criterio de valor. En su complejidad, caben todos estos sentidos en los escritos de filosofía práctica aristotélica. En la versión castellana que hemos tomado, es traducido como palabra. YARZA, Florencio Sebastián. Diccionario Griegoespañol, Barcelona, 1954, p. 849

${ }^{20}$ ARISTÓTELES. Política, [Traducción de Julián Marías], Madrid, Instituto de Estudios Políticos, 1970. [Pol] 1253 a $11-18$
} 
Este pasaje nos ubica en el centro de las reflexiones filosóficas de las que se deriva la concepción de amistad aristotélica. El filósofo forma parte del presente de la vida comunal en donde se comparte la palabra, el logos. El ejercicio del discurso no es un fin en sí mismo; tiene una orientación ética y política: debe hacer posible el esclarecimiento colectivo de qué sea una vida buena en el seno de la ciudad en donde los contextos son contingentes. Saber cómo actuar juntos exige decisiones meditadas desde valores compartidos.

El filósofo toma como punto de partida lo que denomina "éndoxas". Las éndoxas son opiniones compartidas por la mayoría de las personas y por los sabios. Estas creencias tienen un valor ineludible para Aristóteles porque contienen las certezas que se han ido consolidando en el pensamiento comunitario a partir de las cuales algo se nombra y se explica $^{21}$. En este sentido las éndoxas son consideradas como la materia prima de una investigación y constituyen la frontera epistemológica sobre la que se desarrolla una justificación acorde al objeto :

Aquí, como en los demás casos, debemos establecer las apariencias (phāinómena) e investigar en primer lugar las dificultades que presentan para probar después, si es posible, la verdad de todas las opiniones generalmente admitidas (ta éndoxa) sobre estas experiencias: y, si ello no es posible, la mayoría y las más autorizadas. Pues si se resuelven las dificultades y quedan en pie las opiniones comunes, la demostración será suficiente. ${ }^{22}$

La noción aristotélica de phāinómena integra el plano ontológico y semántico en un concepto laxo de experiencia. Lo observado e interpretado por quienes comparten no sólo la pertenencia a una especie sino una forma de vida cultural en común constituye una

\footnotetext{
${ }^{21}$ NUSSBAUM, Martha. La Fragilidad del bien. Fortuna y ética en la tragedia y la filosofía griega, Madrid, Machado Libros. Colección La barca de la medusa, 2004. (en adelante FB p. 313). CHICHI, Graciela. "Opinión mayoritaria "endoxon" y verdad en el diálogo aristotélico", Revista de Filosofía y Teoría Política N³1-32, 1996. pp. 64-75 disponible en:

http://www.fuentesmemoria.fahce.unlp.edu.ar/art:revistas/pr2557/pr.557.pdf

22 Op. Cit. ARISTÓTELES, EN, 1145 b 1 y Sgs.
} 
unidad indiscernible en la que el pensador intentará aproximarse a la verdad creíble y aceptable para su comunidad.

La polis, como señalamos, es una comunidad elegida en tanto se orienta a la realización de una vida "buena" para los ciudadanos ${ }^{23}$. Esta vida tiene un nombre en la comunidad: eudaimonía, (traducido comúnmente por felicidad). Así se expresa esta segunda éndoxa fundamental:“(...) casi todo el mundo está de acuerdo en cuanto a su nombre, pues tanto la multitud como los estudiosos dicen que es la felicidad (eudaimonía) y admiten en que vivir bien (eu zēn) y obrar bien (eu práten) es lo mismo que ser feliz." ${ }^{24}$. El término eudaimonía está formado por el prefijo "eu" que significa "bueno" y "daimon" “espíritu guardián" (exterior al alma propia) ${ }^{25}$. El filósofo considera que esta convicción compartida sobre el bien es el principio ( $a r k h \bar{e})$ de la vida política y sobre éste desarrolla su posición ética. Veamos con más detalle este concepto.

La buena vida depende en gran parte de esa buena suerte -generalmente injustaque tengamos las personas. Este parecer era compartido también en los tiempos de Aristóteles: "La mayoría supone que la vida eudaimon es la vida afortunada o que no carece de buena fortuna; y sin duda están en lo cierto porque sin los bienes exteriores sometidos a la fortuna, no es posible ser eudaimon". ${ }^{26}$ Incluso, hay quien piensa que una buena vida es únicamente tener buena suerte ${ }^{27}$. Sin duda se trata de una creencia ampliamente aceptada que el filósofo no puede menospreciar. El mismo nombre “eudaimonía" parece referirse a este factor como el elemento esencial de la felicidad.

\footnotetext{
${ }^{23}$ Para Aristóteles, sólo el ciudadano por ser libre e igual poseía la condición humana completa para gozar de una vida buena. Este restringido rango -que refleja los límítes socio-históricos del pensamiento del filósofo- no invalida el potencial semántico y emancipatorio de su teoría del bien humano en tanto se amplíe el reconocimiento del carácter político de otros grupos humanos . Ver GUARIGLIA, Osvaldo. “Democracia: origen, concepto y evolución según Aristóteles en DOXA, Cuadernos de Filosofía del Derecho, 33 (2010) pp. 157-190

${ }^{24}$ Op. Cit. ARISTÓTELES, EN 1095 a 18-21

${ }^{25}$ YARZA, Sebastián. Diccionario griego-español, Barcelona, Sopena, 1954.

${ }^{26}$ ARISTÓTELES. La gran moral, [traducción de Patricio de Azcárate], Buenos Aires, Espasa CalpeColección Austral, 1942. [MM] 1206 b 30-5

${ }^{27}$ Op. Cit. ARISTÓTELES, EN, 1099 b 7-8
} 
No obstante, filósofos ilustres como Platón -recordemos que en el seno de su Academia se desarrolló el pensamiento de Aristóteles- sostuvieron que el Bien debía ser algo invulnerable a la contingencia, un objeto posible de ser alcanzado a partir de los esfuerzos sistemáticos de una vida ascética orientada a la sabiduría. Siendo el Bien algo estable, eterno y perfecto (República VI y VII), una vida que buscara el valor auténtico debería desprenderse de la inestabilidad de lo transitorio -tanto por el proceso errático que supone depender de lo contingente como por su naturaleza perecedera-. Para el pensamiento platónico, la mejor vida será aquella en donde la más alta función racional, el noûs, contemple y se haga una con el más alto orden del $\operatorname{ser}^{28}$ reflejando tal orden en el cultivo de las virtudes morales. Una vida resuelta en forma autárquica, ajena a los avatares de la fortuna. En tiempos de Aristóteles es probable que estas ideas hubieran sido motivo de discusión en el círculo de sus discípulos. ${ }^{29}$

\section{La amistad: un valor intrínseco de la vida humana}

Para Aristóteles, la búsqueda de la felicidad comprende una concepción social o común del bien que se articula colaborativamente en distintos vínculos: “(...) nadie querría tener todas las cosas buenas del mundo a condición de estar solo. Porque el ser humano es una criatura política y propensa naturalmente a la convivencia. ${ }^{\prime 30}$ Dado el carácter complejo de las distintas relaciones que el filósofo describe con el término philía algunos autores lo traducen por "amistad" o por "amor"31; Scholeimeier ${ }^{32}$ considera que el término philía es un homónimo que tiene tanto un significado general de "relación social" como uno específico relacionado con la vida virtuosa y el deseo del bien. Sherman ${ }^{33}$

\footnotetext{
${ }^{28}$ SANTAS, G. "The forms of the good in Plato's Republica", Philosophical Inquiry, 2, 1980. pp. 374-403.

${ }^{29}$ Op. Cit. NUSSBAUM, Martha. FB, p. 205

${ }^{30}$ Op. Cit. ARISTÓTELES, EN 1169 b 16-19

${ }^{31}$ Op. Cit. NUSSBAUM, Martha. FB, p. 432

32 SCHOLLEMEIER, Paul. Other selves: Aristotle on personal and political friendship, Albany, State University of New York Press, 1994. p.15

${ }^{33}$ SHERMAN, Nancy. The Fabric of Character. Aristotle's Theory of Virtue, New York, Clarendon PressOxford, 1989. p.128
} 
supone una núcleo central de significados basándose en lo que denomina "la naturaleza colaborativa del buen vivir o de la eudaimonía".

El ejercicio de virtudes como la justicia, la magnanimidad, la generosidad, la moderación, la valentía requieren el encuentro con otros congéneres con sus expectativas y necesidades. Las acciones humanas, en el ámbito en el que se expresan, son intrínsecamente sociales: "consideramos a los amigos uno de los mayores bienes y la falta de philía y la soledad algo terrible porque nuestra vida y nuestras relaciones voluntarias son con los amigos.." ${ }^{34}$ Las auténticas relaciones de amistad comportan siempre una reciprocidad y un propósito de beneficio entre quienes se relacionan ${ }^{35}$. Aunque la justicia es la virtud indispensable de la polis ${ }^{36}$, la amistad la supera: "cuando los hombres son amigos, ninguna necesidad hay de justicia, mientras que aún siendo justos necesitan además de la amistad.."177

El deseo que anima la amistad virtuosa o perfecta (teleia philía) es el bien recíproco en términos absolutos “(...) es elegible por sí misma y parece consistir más en querer que en ser querido". Esta amistad contiene un componente de entrega desinteresada que Aristóteles considera realizado paradigmáticamente en el amor maternal: “(...) señal de ello es que las madres se complacen en querer, pues algunas dan a sus hijos para que reciban crianza y educación, con tal de saber de ellos los siguen queriendo sin pretender que su cariño sea correspondido (...). ${ }^{\prime 38}$ La amistad virtuosa se caracteriza por la confianza mutua, la semejanza en el carácter y las expectativas, el sentimiento de placer por la compañía, la mutua ayuda, el tiempo compartido y el trato asiduo. Todo esto otorga a la relación una gran estabilidad ${ }^{39}$ preservándola de la calumnia

\footnotetext{
${ }^{34}$ Op. Cit. ARISTÓTELES, EE 12345 b 32 30)

${ }^{37}$ Op. Cit. ARISTÓTELES, EN 1155 a $26-28$

${ }^{38}$ Op. Cit. ARISTÓTELES, EN 1159 a $25-33$

${ }^{39}$ Op. Cit. ARISTÓTELES, EN 1157 b 13-15
}

35 Op. Cit. ARISTÓTELES, Ret. 1380 b 35, 1381. Sin embargo cabe aclarar que para Aristóteles hay amistades que los son sólo de "nombre". Se trata de esas relaciones donde se busca o bien el placer o la propia conveniencia. En este caso, es "accidental" la reciprocidad mencionada. (EN 1156 a 15-21)

${ }^{36}$ Para el filósofo la justicia es la virtud que produce y preserva el bien público en la polis ya que, en un sentido absoluto quien obra bien es justo: "En la justicia se dan, juntas, todas las virtudes." (EN 1129 b 29- 
(diabolē) malintencionada. Nadie creerá en la difamación de un amigo cuya bondad y desinterés se ha verificado en la convivencia compartiendo juntos prosperidad e infortunio; por esto afirma el filósofo que "no es fácil creer lo que nadie diga sobre un amigo a quien uno mismo ha puesto a prueba durante mucho tiempo" ${ }^{40}$.

A través del trato y el deseo de vivir y obrar bien juntos, los amigos se van haciendo semejantes en actitudes y sentimientos y encuentran en la mutua compañía un valor intrínseco: "La amistad es, en efecto, compartir (...) y sea lo que fuere aquello en que cada uno hace consistir la vida o por lo que quiere vivir, en eso quiere vivir con su philos. ${ }^{41}$ En el marco de estas condiciones de intimidad y experiencia, se comprende que estas amistades sean escasas en número y difíciles de $\operatorname{lograr}^{42}$ y que la falta de trato pueda deteriorarlas hasta llegar incluso a su disolución ${ }^{43}$.

\section{El amor a sí mismo y el amigo como otro yo}

La amistad virtuosa se nutre - y a la vez fortalece- de la relación que el hombre bueno tiene consigo mismo: "hemos dicho que todos los sentimientos amistosos provienen de uno mismo y alcanzan después a los demás (...) porque cada uno es el mejor amigo de sí mismo y por lo tanto, debemos querernos sobre todo a nosotros mismos". ${ }^{44}$ Como disposición virtuosa, el amor a sí mismo implica el conocimiento de sí, el autoexamen y la búsqueda del bien. De acuerdo con la reflexión de Aristóteles, el amor virtuoso a nosotros mismos constituye una especie de justicia interna que se dice por analogía y metafóricamente ${ }^{45}$ respecto de la justicia política. En palabras de Aristóteles "Ilamamos justo a lo que es índole para producir y preservar la eudaimonía y sus elementos para la comunidad política." ${ }^{\prime 46}$ Justo consigo mismo será predicable de la relación del alma entre la parte racional y la irracional ya que "parece que también ellas

\footnotetext{
${ }^{40}$ Op. Cit. ARISTÓTELES, Ret. 1381 a 30

${ }^{41}$ Op. Cit. ARISTÓTELES, EN 1172 1-6

${ }^{42}$ Op. Cit. ARISTÓTELES, EN 1158 a $11-18$

${ }^{43}$ Op. Cit. ARISTÓTELES, EN 1157 b 7-9

${ }^{44}$ Op. Cit. ARISTÓTELES, EN 1168 b 9-10

${ }^{45}$ Op. Cit. ARISTÓTELES, EN 1138 b 5

${ }^{46}$ Op. Cit. ARISTÓTELES, EN 1129 b 18-19
} 
tienen entre sí una justicia como la que existe entre gobernante y gobernado." ${ }^{\prime 47} \mathrm{Sin}$ embargo, la amistad virtuosa comporta la mutua corrección y el mejoramiento ${ }^{48}$ ya que es difícil observarse a sí mismo y examinar la propia vida sin cierta ceguera ante nuestras propias limitaciones. Por el contrario, "es más fácil mirar a otro que a nosotros mismos" 49 y ver en ellos los defectos que no somos capaces de percibir en nosotros mismos “(...) como es evidente por los reproches que dirigimos a los demás sin darnos cuenta que nosotros hacemos las mismas cosas." ${ }^{50}$ Justamente la relación con un amigo virtuoso habilita esta mirada exclusiva sobre uno mismo porque el amigo es como un "segundo yo" que aprecia con cariño y buena predisposición nuestra situación y el desarrollo de nuestro carácter permitiéndonos tomar distancia y corregir aquello que debamos:

Si alguien mirando a su amigo, ve qué es y de qué carácter (éthos), el phílos si imaginamos la philía más intensa- le parecerá un segundo yo, como en el dicho "éste es mi segundo Heracles". Así pues, ya que, como han dicho algunos sabios conocerse a sí mismo es lo más difícil y también lo más agradable (...) cuando deseamos ver nuestro rostro nos miramos en un espejo, de forma similar cuando queremos conocernos a nosotros mismos miramos al amigo; porque, como decimos, el amigo es otro yo. ${ }^{51}$

Es claro que la amistad hacia uno mismo y hacia los amigos, se alimenta recíprocamente de sentimientos de mutuo interés y respeto que promueven, asimismo, una búsqueda de emulación y corrección fraternas. Las relaciones virtuosas de philía penetran conformando la relación entre la razón y las tendencias apetitivas y emocionales. Mediante la práctica reflexiva y perseverante se desarrollarán héxis ${ }^{52}$ virtuosas como la temperancia (sofrosine) y la magnanimidad (megalopsichía); en el seno

\footnotetext{
${ }^{47}$ Op. Cit. ARISTÓTELES, EN 1138 b 12-13

${ }^{48}$ Op. Cit. ARISTÓTELES, EN 1172 a 12-16

${ }^{49}$ Op. Cit. ARISTÓTELES, EN 1169 b 33-34

${ }^{50}$ Op. Cit. ARISTÓTELES, MM 12130 a 5-12

${ }^{51}$ Op. Cit. ARISTÓTELES, MM 12130 a 20-26

${ }^{52}$ Las virtudes (areté) son para Aristóteles, hábitos (héxis) electivos. (EN 1106b 35)
} 
de esta amistad, prosperará fundamentalmente la virtud intelectual de la prudencia o frónesis ${ }^{53}$ decisiva para conducir el diálogo y la reflexión sobre las diferentes situaciones de la vida, orientando el proceso de deliberación (bouléuesthai) en búsqueda de la mejor decisión.

La amistad es un vínculo que no obedece a un cálculo previo, los motivos para iniciar una amistad pueden ser fortuitos: tener gustos y caracteres similares, la cercanía en edad y experiencias, el mutuo placer. Sostener esa amistad y formarse en ella sí será motivo de elección recíproca. La amistad virtuosa es propia de personas libres e iguales. La amistad es, en sí misma, una relación política en tanto que la libertad y la igualdad son dos de las propiedades necesarias que identifican al ciudadano (polites) y lo inscriben en una comunidad más amplia que es la ciudad (polis): "Al mismo tiempo, debe pensarse que ningún ciudadano se pertenece a sí mismo, sino que todos pertenecen a la ciudad, puesto que cada uno es parte de ella." ${ }^{54}$

La ciudad es una comunidad elegida; en ella, el tipo de vínculo que los ciudadanos establezcan entre sí como miembros de la ciudad también será fruto de su elección. Aristóteles expresa su desacuerdo con la doctrina que funda el origen de la sociedad en el autointerés y la salvaguarda de los derechos individuales como "si las relaciones mutuas una vez unidos fueran iguales que cuando estaban separados" ${ }^{\prime 55}$, considera que de un contrato semejante no puede derivarse una cohesión comunitaria. Evitar la mutua injusticia y facilitar el intercambio constituyen fines subsidiarios frente al valor de la misma vida política que necesariamente se define en base a relaciones de amistad.

\footnotetext{
${ }^{53}$ La frónesis involucra un tipo de saber no científico sino particular, indefinido e inestable. La función de esta virtud intelectual es identificar cómo debemos obrar en una situación particular ( EN 1140 b 4- 7). La frónesis comprende tres condiciones mutuamente referidas: a) un saber científico acerca de las causas que gobiernan las circunstancias de la acción, b) una familiaridad o experiencia (empiria) vital plasmada en un reservorio de reglas prácticas, - obtenidas por inducción a partir de la reflexión sistemática sobre la actuación propia o de otros en casos análogos; y c) una sensibilidad para captar los detalles relevantes del contexto en el que la acción virtuosa debe realizarse.

${ }^{54}$ Op. Cit. ARISTÓTELES, Pol 1337 a 27-29

${ }^{55}$ Op. Cit. ARISTÓTELES, Pol 1280 b 28-30
} 


\section{La homonoia o amistad política}

Aristóteles denomina homonoia (concordia) al vínculo que construye "politicidad" en una comunidad manteniéndola unida en el deseo del bien común: "un sentimiento amistoso y no una mera igualdad de opinión (...) por el cual los ciudadanos piensan de la misma manera sobre lo que les conviene, eligen las mismas cosas y hacen juntos lo que de común han acordado." ${ }^{56}$. La homonoia es fruto y extensión de la philía virtuosa que guarda continuidad entre el amor a sí mismo y el amor a los conciudadanos: "Esta clase de unanimidad se da en los buenos, pues éstos están de acuerdo consigo mismos y entre sí y teniendo, por así decirlo, un mismo deseo (...) quieren a la vez lo justo y lo conveniente y a esto aspiran en común." ${ }^{57}$ En este punto cabe preguntarse por el ámbito en donde se origina y se desarrolla esta forma de amistad por la cual los ciudadanos piensan, eligen y hacen juntos lo que han acordado en común.

En el Libro Tercero de la Política Aristóteles define la ciudadanía como una magistratura a la que le corresponde un ejercicio del poder político que consiste en deliberar como miembro de la asamblea (ekklesía) y juzgar. ${ }^{58}$

En su búsqueda de la mejor constitución política posible ${ }^{59}$, Aristóteles compone su propuesta tomando de todos los regímenes políticos ${ }^{60}$ las mejores instituciones; entre éstas, otorga al Consejo (Boulé) -una institución propia de los regímenes democráticos ${ }^{61}$ una importancia decisiva en la expresión política del logos:

Y junto a todas estas magistraturas está la suprema sobre todas, que muchas veces tiene en su mano la decisión final o la implantación de una medida, u ocupa la presidencia de la multitud, donde tiene la soberanía el pueblo, (...) en algunos lugares

\footnotetext{
${ }^{56}$ Op. Cit. ARISTÓTELES, EN 1167 b 22-30

${ }^{57}$ Op. Cit. ARISTÓTELES, EN 1167 b 4-8

${ }^{58}$ Op. Cit. ARISTÓTELES, Pol 1275 b 28-31

${ }^{59}$ Op. Cit. ARISTÓTELES, Pol 1295 a 25 y ss.

${ }^{60}$ Aristóteles compiló y analizó ciento cincuenta y ocho constituciones correspondientes a ciudades helenas y orientales. Sólo se ha conservado Constitución de Atenas, obra hallada fortuitamente en Egipto en 1890. (BALLESTEROS, J. Aristóteles y la comunidad política, Santa Fe, Universidad Católica de Santa Fe, 2012. p. 33)

${ }^{61}$ Op. Cit. ARISTÓTELES, Pol 1317 b 31
} 
se llaman comisiones dictaminadoras, porque deliberan previamente, y donde gobierna la mayoría, más bien Consejo (Boulé). ${ }^{62}$

Las leyes son la conclusión de los procesos de deliberación pública en la asamblea, son fruto de procesos colectivos de toma de decisiones y consuman el bien práctico posible a ser realizado por los ciudadanos. Se espera que la obediencia a las leyes promulgadas de esta manera- vaya promoviendo la vida virtuosa de los ciudadanos: "la ley tiene una fuerza necesaria, al ser una regla (logos) de cierta prudencia e inteligencia." ${ }^{63}$ Las leyes son la expresión discursiva de las decisiones acerca del bien común decididas en el ámbito del Consejo. Comprometen a los ciudadanos en tanto partícipes racionales por cuanto la acción es la consecuencia necesaria de toda deliberación racional ${ }^{64}$.

Aristóteles señala que existe una virtud propia de los hombres libres (eleuthéron) que es el "imperio político" (politicon arkhé) por la cual "se manda a los de la misma clase y a los libres" y que sólo puede aprenderse habiendo obedecido: "por eso, se dice con razón que no puede mandar bien quien no ha obedecido (...) el buen ciudadano tiene que saber y poder tanto obedecer como mandar, y la virtud del ciudadano consiste en conocer el gobierno de los hombres libres desde ambos puntos de vista." ${ }^{65}$

\section{El ciudadano consejero}

En la Retórica, Aristóteles describe un género novedoso para las prácticas de su época ${ }^{66}$ : la oratoria deliberativa o consejo destinada a orientar la asamblea de ciudadanos para la toma de decisiones oportunas: “(...) en las cuestiones importantes nos hacemos

\footnotetext{
${ }^{62}$ Op. Cit. ARISTÓTELES, Pol 1322 b 11-17

${ }^{63}$ Op. Cit. ARISTÓTELES, EN 1180 a 21-22

${ }^{64}$ Se trata de la doctrina del "silogismo práctico" en la que se esquematiza el proceso de deliberación que conduce a la toma de decisiones. En este argumento, la premisa mayor corresponde a consideraciones acerca de lo valioso o bueno a perseguir; mientras que las "premisas menores" se refieren al cálculo instrumental de los medios disponibles. El necesario balance entre los deseos y los medios conduce a la comprensión del "bien realizable" en una situación particular. Ver el excelente desarrollo de esta noción en NUSSBAUM, Martha, Aristotle's Motu Animalium, Princeton, 1976.

${ }^{65}$ Op. Cit. ARISTÓTELES, Pol 1277 b 13-16

${ }^{66}$ MARAFIOTI, Roberto. Los patrones de la argumentación. La argumentación en los clásicos y en el siglo XX, Buenos Aires, Ed. Biblos, 2003. p. 32.
} 
aconsejar por otros porque desconfiamos de nosotros mismos y no nos creemos suficientes para decidir" ${ }^{67}$ Esta práctica política es crucial para el desarrollo de la amistad cívica. La oratoria deliberativa está orientada a persuadir o a disuadir respecto de un curso de acción, su horizonte es el futuro. ${ }^{68}$ Tomar la mejor decisión requiere escuchar un consejero "digno de fe", Aristóteles distingue tres causas de esta confianza: la prudencia (frónesis), la virtud (areté) y la benevolencia (eúnoia). Aristóteles considera que la bondad del carácter ${ }^{69}$ desarrolla nuestra habilidad para discernir lo que es bueno, de ser sensibles a los rasgos moralmente valiosos de una situación; en consecuencia, nos predispone también a dar consejos. Por eso la prudencia del orador deliberativo y su virtud lo hacen digno de confianza ante quienes, a partir de sus consejos, deberán acordar una decisión que se oriente al logro de lo que es mejor para la ciudad: “(...) para el orador que aconseja es finalidad lo conveniente, y se delibera, no sobre la finalidad sino sobre lo conducente a la finalidad y estos medios son lo conveniente en cuanto a las acciones y lo conveniente es el bien." 70

Con respecto a la eúnoia o benevolencia, Aristóteles la define en la Ética como un tipo particular de sentimiento amistoso: “(...) de los que así desean el bien del otro decimos que son benévolos si de la parte del otro produce el mismo sentimiento, pues cuando la benevolencia es recíproca decimos que es amistad (philía)". El consejero benevolente demuestra una predisposición desinteresada por beneficiar a sus conciudadanos aún sin mediar el conocimiento personal ni el trato. ${ }^{71} \mathrm{El}$ orador consejero habla en el seno de la asamblea de ciudadanos presentando argumentos acerca de lo que

\footnotetext{
${ }^{67}$ Op. Cit. ARISTÓTELES, EN 1112 b 12-14

${ }^{68}$ Op. Cit. ARISTÓTELES, Ret 1358 b 14-15

${ }^{69}$ Considero de gran interés y originalidad que Aristóteles observe que las formas habituales de comportarnos inciden en nuestras maneras de comprender y valorar lo que nos rodea y a la vez de discernir el valor a realizar en las diferentes circunstancias en las que nos encontramos:

"Los razonamientos de orden práctico tienen un principio, por ejemplo, "puesto que el fin es este" o "puesto que lo mejor es esto", sea cual fuere, y este fin no aparece claro sino al bueno, porque la maldad nos pervierte y hace que nos engañemos en cuanto a los principios de la acción. De modo que evidentemente es imposible ser prudentes no siendo buenos." EN 1144 a 31-35

${ }^{70}$ Op. Cit. ARISTÓTELES, Ret 1362 a $17-20$

${ }^{71}$ Op. Cit. ARISTÓTELES, EN 1167 a 13-17
} 
sea mejor para la polis, inspirando confianza a sus conciudadanos: "por eso pensamos que Pericles y los que son como él son prudentes porque pueden ver lo que es bueno para ellos y para los hombres y pensamos que esta es una cualidad propia de los administradores y de los políticos". ${ }^{72}$

Los temas de esta oratoria deliberativa versan sobre el financiamiento, la guerra, el comercio, la legislación; áreas cruciales para el desarrollo de la ciudad. ${ }^{73} \mathrm{El}$ tratamiento de cada una de estas cuestiones requiere un amplio conocimiento técnico, estratégico y fundamentalmente histórico. ${ }^{74}$ En tal sentido, Aristóteles enfatiza que el tipo de argumento apropiado para la oratoria deliberativa es el ejemplo (paradígmata): "Ios ejemplos son lo más apropiado para los deliberativos, ya que por lo pasado juzgamos augurando el futuro." 75

La incertidumbre de lo que "puede ser de otra manera" es compensada por la confianza en aquellos que por su formación y experiencia pueden anticipar que iguales causas podrían llevar a iguales consecuencias, que por su desinterés y disposición bienhechora hacia los conciudadanos ofrecen sus consejos a consideración de la asamblea soberana. Un punto decisivo es el discernimiento acerca de la buena legislación "pues en las leyes está la salvación (sotería) de la ciudad". ${ }^{76}$ Por el contrario, quien se interesara por manipular las decisiones a favor de una facción y en contra de la unidad de la polis prescindiría justamente de la deliberación en asamblea, intentando convencer sobre lo inconveniente y lo injusto: “(...) muchas veces prescinden de lo demás, pero lo que no reconocerán nunca es que aconsejan cosas inconvenientes o disuaden de lo provechoso." 77

La imagen de este último orador es idéntica a la que proyecta el orador bueno y prudente. Si la confianza de los ciudadanos y su decisión soberana sólo descansara en un

\footnotetext{
${ }^{72}$ Op. Cit. ARISTÓTELES, EN 1140 b 8-11

${ }^{73}$ Op. Cit. ARISTÓTELES, Ret 1359 a 19-23

${ }^{74}$ Op. Cit. ARISTÓTELES, Ret 1359 b 29-30/1368 a 30-31/ 1360 a 6-7

75 Op. Cit. ARISTÓTELES, Ret 1393 a 30- 1393 b 5/ 1394 a 8-15

${ }^{76}$ Op. Cit. ARISTÓTELES, Ret 1360 a 29

${ }^{77}$ Op. Cit. ARISTÓTELES, Ret 1358 a 35-40
} 
discurso hábil, la libertad política se vería esencialmente afectada y con ella el valor propio de la democracia que se expresa en el Consejo de los ciudadanos: "El fundamento del régimen democrático es la libertad (...) y siendo esto lo justo, forzosamente tiene que ser soberana la muchedumbre y lo que apruebe la mayoría (...)" ${ }^{78}$ Como resultado de estos procesos de deliberación, los ciudadanos se esclarecerán sobre la interpretación de las circunstancias, sobre las expectativas a futuro comprometiéndose a lograr cooperativamente lo que sea bueno para el conjunto.

En el ejercicio y el desarrollo de esta prudencia colectiva juega tanto la apropiación de la experiencia común, como la consideración de las circunstancias presentes con vistas a ese horizonte de valor incierto pero posible. Siendo las acciones parte de los eventos que pueden ser o no ser, el ser humano se realiza en el tiempo porque es el único ser viviente "capaz de proyectarse hacia el futuro resistiendo el deleite que se le presenta como absoluto cuando no se ve lo futuro." ${ }^{79}$

\section{Pensar a Aristóteles en nuestro tiempo}

Aristóteles concibió su obra como un proyecto abierto, por eso parece simplemente haber querido trazar algunas coordenadas normativas. ${ }^{80}$

En tal sentido debemos entender el establecimiento de la eudaimonía como principio rector de la vida política. Fin que necesariamente debe ser objeto y compromiso de la deliberación ciudadana en el marco de la convivencia amistosa entre personas que se reconocen libres e iguales. A diferencia de lo que señala Agamben, Aristóteles consideró que la proximidad vital entre los amigos habilitaba una mirada más exacta y profunda sobre uno mismo, sobre la relación y sobre las condiciones concretas de la vida buena. A la vez, consideró que tales vínculos generaban disposiciones recíprocas para

\footnotetext{
${ }^{78}$ Op. Cit. ARISTÓTELES, Pol. 1137 b1-6

${ }^{79}$ Op. Cit. ARISTÓTELES, DA 433 b 7

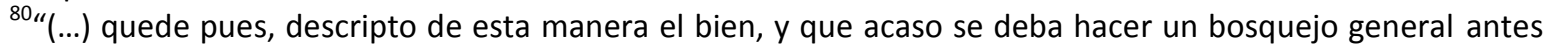
de describirlo detalladamente, parece que cualquiera podría continuar y articular lo que está bien bosquejado y que el tiempo en estas cosas es buen inventor y colaborador." ARISTÓTELES, EN 1098 a 19-22
} 
comprender la situación de los amigos, descubrir sus necesidades, sostener su vida material y espiritual en pos de la excelencia.

La teoría aristotélica de la eudaimonía ha sido considerada antecedente del concepto de derechos humanos ${ }^{81}$ y sigue vigente en la reivindicación de la política como contexto constructivo y generador de condiciones favorables al desarrollo y cuidado de la vida. En este sentido, es destacable que para el filósofo sea en el ejercicio del diálogo compartido y de la convivencia donde se articulen los procesos de apropiación de la historia y las expectativas a futuro. En este marco, la misma vida política no sólo constituye un proceso pedagógico que refuerza y estabiliza vínculos de justicia y amistad social generando dinámicamente legitimidad política, sino que a la vez es un valor en sí mismo.

En el breve escrito que hemos considerado, Agamben parece sugerir que la práctica deliberada de la amistad hace consciente y deseable la vida propia y la de los demás, abriendo un espacio es donde el sentir, pensar y actuar en conjunto constatan la propia existencia y su valor.

La amistad parece ser la contracara de la situación del homo sacer. Giorgio Agamben acuña esta expresión para nombrar el fenómeno de la vida humana despojada de toda dignidad ética e institucionalidad: vida desnuda cuyo lugar simbólico ( $\mathrm{y}$, a veces, físico) es el campo de concentración. Vidas cuya vulneración no constituye crimen ni pecado ${ }^{82}$.

En su célebre obra ${ }^{83}$, Agamben recupera la antigua institución romana nombrada en el sintagma "homo sacer" ${ }^{\prime 4}$. Homo sacer es aquel sujeto humano cuya muerte no es objeto de condena y cuya vida tampoco pertenece a los dioses, es insacrificable. Sin pretender en este trabajo abundar en la complejidad del concepto, quisiera señalar que

\footnotetext{
${ }^{81}$ Así argumenta NUSSBAUM, Martha. Las fronteras de la justicia, Barcelona, Ed. Paidós, 2007. pp. 385-394

${ }^{82}$ CASTRO, Edgardo. Giorgio Agamben. Una arqueología de la potencia, San Martín, Universidad Nacional de San Martín, 2008. pp. 57, 60-61.

${ }^{83}$ AGAMBEN, Giorgio. Homo Sacer. El poder soberano y la nuda vida. Trad. Gimeno Cuspinera, Valencia, Pre textos, 2006 [HS]

${ }^{84}$ Op. Cit. AGAMBEN [HS], p.93
} 
Agamben considera que la condición homo sacer sintetiza el punto originario del orden político. En efecto, el poder soberano es aquel capaz de matar sin condena. Bajo el poder soberano el hombre se vuelve "sagrado" pero no en el sentido de "bendecido" o "consagrado" a un orden divino sino en el sentido de ser una vida "disponible" en el orden humano ${ }^{85}$. El homo sacer se excluye de la comunidad natural aceptando a la vez quedar potencialmente excluido -vía su supresión- de la comunidad política:

"Todo sucede como si los ciudadanos varones tuvieran que pagar su participación en la vida política como una sujeción incondicionada a un poder de muerte, como si la vida sólo pudiera entrar en la ciudad bajo la doble excepción de poder recibir la muerte impunemente y de ser insacrificable (...) ni bíos político ni zoé natural, la vida sagrada es la zona de indistinción en la que implicándose y excluyéndose entre sí, ambas se constituyen recíprocamente..." ${ }^{86}$

El poder soberano dispone de la vida de los ciudadanos no sólo en el control de su desarrollo sino en el establecimiento de las condiciones de su "dignidad". De tal manera, algunas vidas se "sacralizan" paradójicamente como "indignas". Las estipulaciones del poder soberano categorizan las vidas habilitando los lugares para su muerte impune ${ }^{87}$.

Una vez más Aristóteles, al considerar la amistad no sólo como una necesidad humana sino como un proyecto ético y político, trazó las líneas para descubrir el potencial emancipador de esta relación en lo que atañe al reconocimiento de la humanidad en las personas concretas, no sólo en términos simbólicos sino también materiales. "Amigo" entraña la proximidad del "otro" en "mi vida". En la amistad se da el continuum de lo personal y lo político retroalimentándose y dotando de sentido y valor la vida humana. ${ }^{88}$ En la actualidad, esta antigua visión de la amistad parece verificarse en la génesis y

\footnotetext{
${ }^{85}$ Op. Cit. AGAMBEN [HS], p.107

${ }^{86}$ Op. Cit. AGAMBEN [HS], p.117

${ }^{87}$ Agamben menciona los campos de concentración europeos, la situación de los refugiados y la desnacionalización de ciudadanos realizados en Francia y en Bélgica por ser considerados peligrosos. Op. Cit. AGAMBEN, [HS] (p. 167, p. 175 y sig.)

${ }^{88}$ Op. Cit. AGAMBEN, Profanaciones, p. 4
} 
dinámica de los movimientos sociales reivindicatorios de derechos ${ }^{89}$. En la constitución de lazos colectivos y solidarios; en la necesidad de esclarecerse sobre la situación de infortunio y la transformación a futuro; en la búsqueda de la concordia o homonoia procurando superar la enemistad y las divisiones, parecen nuevamente vivificarse las antiguas reflexiones del filósofo.

Esta separación entre poder y vida sobre la que reflexiona Agamben es justamente la que impugna Aristóteles al comprender lo político como un poder que surge de la palabra y la voluntad del bien recíproco que funda una comunidad basada en la benevolencia y la amistad.

\section{Bibliografía}

- AgAMBeN, Giorgio. Homo Sacer. El poder soberano y la nuda vida. Trad. Gimeno Cuspinera, Valencia, Pre textos, 2006

- $\quad------$ Profanaciones, Buenos Aires, Adriana Hidalgo Editora, 2005

- ARENDT, Hanna. Qué es la política, Barcelona, Paidós, 2005.

- ARISTÓTELES. Ética a Nicómaco, [Traducción de Maria Araujo y Julián Marías], Madrid: Centro de Estudios Constitucionales, 1994

- ------------. La gran moral, [traducción de Patricio de Azcárate], Buenos Aires, Espasa CalpeColección Austral, 1942

- ----------. Política, [Traducción de Julián Marías], Madrid, Instituto de Estudios Políticos, 1970

- BALleSteros, J. Aristóteles y la comunidad política, Santa Fe, Universidad Católica de Santa Fe, 2012

- CASTRO, Edgardo. Giorgio Agamben. Una arqueología de la potencia, San Martín, Universidad Nacional de San Martín, 2008

- CHICHI, Graciela. "Opinión mayoritaria "endoxon" y verdad en el diálogo aristotélico", Revista de Filosofía y Teoría Política N³1-32, 1996

- DERRIDA, Jaques. Políticas de la amistad seguido del oído de Heidegger, Barcelona. Ed. Trotta, 1998.

- GUARIGLIA, Osvaldo. "Democracia: origen, concepto y evolución según Aristóteles en DOXA, Cuadernos de Filosofía del Derecho, 33 (2010)

- KYMLICKA, Will y Wayne NORMAN. "El retorno del ciudadano. Una revisión de la producción reciente en teoría de la ciudadanía." En Cuadernos del CLAEH, 75, Montevideo, 1996

- NUÑEZ, Cintia Itatí, "Las formas de la solidaridad en movimientos de trabajadores desocupados de la ciudad de Resistencia-Chaco" en Sociedad y Discurso № 25 Universiad de Aalborg, 2014

- NUSSBAUM, Martha. La Fragilidad del bien. Fortuna y ética en la tragedia y la filosofía griega, Madrid, Machado Libros. Colección La barca de la medusa, 2004.

- $\quad$------------------. Las fronteras de la justicia, Barcelona, Ed. Paidós, 2007

\footnotetext{
${ }^{89}$ NUÑEZ, Cintia Itatí, "Las formas de la solidaridad en movimientos de trabajadores desocupados de la ciudad de Resistencia-Chaco" en Sociedad y Discurso N $N^{\circ} 25$ Universiad de Aalborg, 2014, pp. 90-114 constituye un interesante estudio sobre la incidencia de los vínculos de amistad en el proceso de organización y gestión de movimientos sociales.
} 
- OVeJero LUCAS, Felix. Proceso Abierto: el socialismo después del socialismo, Barcelona, Kriterios. Tusquets Editores, 2005

- SANTAS, G. "The forms of the good in Plato's Republica", Philosophical Inquiry, 2, 1980.

- SCHOLLEMEIER, Paul. Other selves: Aristotle on personal and political friendship, Albany, State University of New York Press, 1994.

- SHERMAN, Nancy. The Fabric of Character. Aristotle's Theory of Virtue, New York, Clarendon Press-Oxford, 1989

- YARZA, Florencio Sebastián. Diccionario Griego-español, Barcelona, 1954 